\title{
Preparation of glycosylated hydrolysate by liquid fermentation with Cordyceps militaris and characterization of its functional properties
}

\author{
Shuang YANG ${ }^{1}$, Mingzhu ZHENG ${ }^{1 *}$, Sheng $\mathrm{LI}^{1}$, Yu XIAO ${ }^{1}$, Qi ZHOU ${ }^{1}$, Jingsheng LIU $^{1,2 *}$ (D)
}

\begin{abstract}
This study aimed to investigate the potential of a novel preparation strategy for glycosylated hydrolysate by liquid fermentation in order to provide a high-quality glycosylated hydrolysate. Protein solubility, surface hydrophobicity and antioxidant activity were evaluated. The results of Fourier transform infrared spectra demonstrated the occurrence of glycosylation reaction. The results of Fluorescence emission spectroscope revealed the decrease of tertiary conformation stability. Circular dichroism spectra revealed significant decrease in $\alpha$-helix and increase in $\beta$-sheet and random coil by glycosylation reaction. In comparison with zein hydrolysate, glycosylated hydrolysate had lower surface hydrophobicity but higher in solubility and in vitro digestibility due to glycosylation. Glycosylated hydrolysate presented higher ABTS (2,2'-Azinobis [3-ethylbenzothiazoline-6-sulfonic acid]-diammonium salt) and superoxide radicals scavenging activities as well as $\mathrm{Cu}^{2+}$ chelating capacity. It is concluded that the glycosylation confer an open structure and modified properties of zein, and glycosylated hydrolysate is a potential ingredient with better hydration and antioxidant activities than zein hydrolysate.
\end{abstract}

Keywords: zein; glycosylated hydrolysate; Cordyceps militaris; conformational properties; functional properties.

Pratical Application: Zein was modified by liquid fermentation using Cordyceps militaris.

\section{Introduction}

People's demand for protein is growing, which is driven by a rising population and a growing recognition of the importance of protein as a key ingredient for nutrition and health. Dietary protein supplementation is becoming popular, especially for people on athletes, restrictive diets and elderly people. Proteins from dairy and soy are the main sources used in nutritional products. However, zein is one of the chief protein fractions of corn gluten meal (CGM), which is the main co-product of corn wet-milling process (Ozturk \& Mert, 2018). Furthermore, zein is an excellent source of protein. It could have some nutraceutical or pharmaceutical value. However, zein is currently considered undesirable for direct human consumption, and most commonly used in animal feeds or fertilisers. Zein contains a large proportion of hydrophobic amino acids, such as leucine, alanine, proline and isoleucine, and hence it has low solubility in aqueous systems and exhibits relatively stable structures. Zein is difficult to digest in a simulated stomach system (Chuacharoen \& Sabliov, 2016). These properties of zein limit its application in food processing application. However, zein represents an untapped resource of functional ingredients that can be applied to various aspects of food processing.

In recent years, biological treatments have been widely applied to improve protein nutritional and/or functional properties, consisting of enzyme treatment and fermentation, which change the physicochemical and functional properties by changing its structure and conformation (Maux et al., 2018). The zein hydrolysate may be expected to have increased solubility, foaming and emulsifying properties, and can create hypoallergenic nutritional mixtures, and there are many studies have proved these. In addition to enzymatic hydrolysis of protein, glycosylation reaction is one of most studied processes in food science, which widely applied to improve functional properties of protein. The enhancement of the functional and biological properties of glycoproteins is a new frontier being explored by several teams. The Maillard reaction is referred to as non-enzymatic glycosylation, and has been studied extensively as it can significantly improve functional properties of protein. However, the potential adverse effects of the Maillard-type glycosylation cannot be ignored, such as the use of high temperatures (Du et al., 2018) and formation of unhealthy compounds. Compared with normal sugar, amino-sugars have higher reactivity (Kraehenbuehl et al., 2010). Amino sugar has been found in the cell wall of fungi (Dereggi \& Bauer, 2013) and can be used as a potential candidate for glycosylation at mild temperatures (Hrynets et al., 2013). Those literatures implied that glycosylated hydrolysate might be prepared by liquid fermentation with fungi, which would provide a new method to improve some properties of zein.

Since zein hydrolysate contains high proportion of glutamine (23.5\%), the enzymatic glycosylation reaction can occur mainly between zein hydrolysate and saccharides during liquid fermentation by fungi. Therefore, liquid fermentation by fungi can be a potential method for preparation of glycoprotein. In the available literatures, glycosylation reaction derived from liquid fermentation has not been reported so far. In the present study, glycosylated hydrolysate was prepared by liquid fermentation using Cordyceps militaris (C. militaris). Physicochemical and 
functional properties of the glycosylated hydrolysate were evaluated, and the effect of glycosylation reaction on the conformational properties of protein was analyzed.

\section{Materials and methods}

Zein was obtained from Shanghai Ryon Biological Technology, China (purity $>92 \%$ ). C. militaris was preserved in the National Engineering Laboratory for Wheat and Corn Deep Processing (HMJAU 202, Herbarium Mycology of Jilin Agriculture University, Chang Chun, China). All the chemicals were of analytical grade and obtained from Dingguo biotechnology co. LTD (Beijing, China).

\subsection{Preparation of glycosylated hydrolysate}

The preparation of $C$. militaris seeding was the same as method described previously (Yang et al., 2018). C. militaris seeding was broken using a sterilized Blender. Ten-milliliter aliquots of the seeding were inoculated into $500 \mathrm{~mL}$ conical flasks containing $100 \mathrm{~mL}$ medium. The flasks grew with shaking at a speed of $160 \mathrm{r} / \mathrm{min}$. The zein hydrolysate and glycosylated hydrolysate were obtained at fermentation of $6 \mathrm{~d}$ and $14 \mathrm{~d}$. After fermentation, the reaction was terminated by boiling for $5 \mathrm{~min}$. In order to extract the zein hydrolysate and glycosylated hydrolysate, the fermented broths were centrifuged at $4000 \times \mathrm{g}$ for $20 \mathrm{~min}$. The zein hydrolysate and glycosylated hydrolysate were obtained by fraction precipitation with ammonium sulfate at $50 \%$ saturation. The precipitations were dialyzed against water at $4{ }^{\circ} \mathrm{C}$ for $24 \mathrm{~h}$ in order to remove salt and then were freeze-dried. The purified zein hydrolysate and glycosylated hydrolysate were used for characterization of functional and conformational properties.

\subsection{Sodium Dodecyl Sulfide polyacrylamide gel electrophoresis (SDS-PAGE)}

The purified zein hydrolysate and glycosylated hydrolysate were used for the SDS-PAGE experiments. 15\% separating gel and 5\% stacking gel were used. Protein samples were mixed with the sample buffer: $0.5 \mathrm{M}$ Tris- $\mathrm{HCl}, 10 \%$ glycerol, with $5 \%$ $\beta$-mercaptoethanol ( $\beta-\mathrm{ME})$, and $1 \%(\mathrm{w} / \mathrm{v})$ Bromophenol blue ( $\mathrm{pH}$ 6.8). The mixtures were heated at $100{ }^{\circ} \mathrm{C}$ for $5 \mathrm{~min}$, and then centrifuged at $8000 \times \mathrm{g}$ for $30 \mathrm{~s}$. Samples were loaded, and subjected to electrophoresis at a voltage of $80 \mathrm{~V}$ in the stacking gel and $120 \mathrm{~V}$ in the separating gel until the dye reached the bottom of the gel. Then the gels were stained for $5 \mathrm{~h}$ using $0.05 \%$ Coomassie Brilliant Blue R-250 in acetic acid/methanol/water solution (46:227:227, v/v/v) and destained for $12 \mathrm{~h}$ with methanol/acetic acid/water solution (50:75:875, v/v/v).

\subsection{Fourier Transform Infrared (FTIR) spectroscopy analysis}

FTIR spectra of the samples were determined using VERTEX70 spectrometer (Bruker, Rheinstetten, Germany). The measurements were recorded in the frequency range of $4000-400 \mathrm{~cm}^{-1}$. The data was analyzed with Origin 8.5 software (Origin Lab Corp., USA). The experiments were conducted three times.

\subsection{Intrinsic fluorescence emission spectroscopy analysis}

Intrinsic fluorescence emission spectra of the samples were determined according to the method of Ranamukhaarachchi (Ranamukhaarachchi et al., 2017) with some modifications. A fluorescence spectrophotometer (HITACH, Tokyo, Japan) was used. Protein solutions $(1 \mathrm{mg} / \mathrm{mL})$ were prepared in $0.05 \mathrm{mM}$ Tris- $\mathrm{HCl}$ buffer ( $\mathrm{pH}$ 8.8). The protein solutions were excited at $280 \mathrm{~nm}$, and emission spectrum was recorded from 300 to $500 \mathrm{~nm}$ with a slit width of $5 \mathrm{~nm}$. The experiments were conducted three times.

\subsection{Circular Dichroism (CD) analysis}

CD spectra of the samples were determined on a J-815 CD spectrometer (Jasco, Tokyo, Japan). A $1.0 \mathrm{~mm}$ path length quartz cuvette was used. $0.1 \mathrm{mg} / \mathrm{mL}$ of protein solutions were prepared by dissolving samples in $0.05 \mathrm{mM}$ Tris- $\mathrm{HCl}$ buffer $(\mathrm{pH} 8.8)$. All the samples were scanned from 190 to $250 \mathrm{~nm}$. The analysis of the CD spectroscopic data was carried out using the online SELCON3 method in DICHROWEB. The experiments were conducted three times.

\subsection{Amino acid analysis}

A L-8900 amino acid analyzer (Hitachi, Tokyo, Japan) was used to determine the amino acid. The samples $(0.1000 \mathrm{~g})$ were added into $14 \mathrm{~mL}$ hydrolysis tubes, mixed with $10 \mathrm{~mL} \mathrm{HCl}$ $(6 \mathrm{~mol} / \mathrm{L})$. The samples were digested under nitrogen atmosphere at $110^{\circ} \mathrm{C}$ for $22 \mathrm{~h}$. The mixture was dried on water bath, and then was diluted with sodium citrate buffer $(\mathrm{pH} 2.2)$. The samples were filtered with $0.22 \mu \mathrm{m}$ organic filter membranes, and were used for analyzing. The experiments were conducted three times.

\subsection{Solubility}

Solubility of the samples was determined using the method of Zhao et al. (2011), with some modifications. Protein dispersions in deionized water $(1.5 \%, \mathrm{w} / \mathrm{v})$ were stirred magnetically for $120 \mathrm{~min}$, and then $\mathrm{pH}$ was adjusted to the desired values ( $\mathrm{pH} 2-14$ ) using $0.5 \mathrm{M} \mathrm{HCl}$ or $0.5 \mathrm{M} \mathrm{NaOH}$. Then the dispersions were centrifuged at $8000 \times \mathrm{g}$ for $20 \mathrm{~min}$. After appropriate dilution, the protein content of the supernatant was determined by Lowry's method using bovine serum albumin (BSA) as the standard. The protein solubility was expressed as grams of soluble protein per $100 \mathrm{~g}$ of protein. All the determinations were conducted three times.

\subsection{Surface hydrophobicity}

Surface hydrophobicity was determined according to the method of Jiang (Jiang et al., 2018) with some modifications. The samples $(30 \mathrm{mg}$ ) were dispersed in $10 \mathrm{mmol} / \mathrm{L}$ phosphate buffer $(\mathrm{PB})$ at $\mathrm{pH} 7.0$ and incubated at room temperature for $24 \mathrm{~h}$ to facilitate hydration, then centrifuged at $8000 \mathrm{~g}$ for $15 \mathrm{~min}$ and the supernatant was diluted further in PB to obtain various concentrations $(0.01-0.2 \mathrm{mg} / \mathrm{mL})$. The diluted protein solution $(5 \mathrm{~mL})$ was mixed with $25 \mathrm{uL}$ of $8 \mathrm{mmol} / \mathrm{L}$ ANS in $10 \mathrm{mmol} / \mathrm{L}$ $\mathrm{PB}$ and incubated in dark for $15 \mathrm{~min}$. Fluorescence intensity was measured at an excitation wavelength of $390 \mathrm{~nm}$ and an emission wavelength of $470 \mathrm{~nm}$ at a constant slit of $5 \mathrm{~nm}$ using a Versafluor 
Fluorometer System (Spectramax 190, Molecular Device Co., America). The initial slope of the relative fluorescence intensity versus protein concentration $(\mathrm{mg} / \mathrm{mL})$ plot represented an index of the surface hydrophobicity of the sample. The experiments were conducted three times.

\subsection{In vitro digestibility}

In vitro digestibility of the samples was measured by the method of Matemu (Matemu et al., 2009). Trichloroacetic acid (TCA)-soluble nitrogen released into the supernatant was assessed by a spectrophotometer at $280 \mathrm{~nm}$, after dilution of the collected supernatant by water. The absorbencies were used to reflect in vitro digestibility of samples. The experiments were conducted three times.

\subsection{In vitro antioxidant activities}

The antioxidant activities including DPPH, ABTS and superoxide radicals scavenging assays and metal ions chelating capacity of the glycosylated zein were investigated in vitro. The scavenging effects of the samples on DPPH free radical were measured according to the method of Xia et al. (2012). A procedure presented by Re et al. (1999) was applied to measure the ABTS radical scavenging activity. A procedure presented by Kim (2013) was applied to determine $\mathrm{Cu}^{2+}$-chelating activity. The scavenging effects of the samples on superoxide radical were determined according to the method of Wang et al. (2014). The experiments were conducted in three replicates.

\subsection{Statistical analysis}

All the diagrams were plotted by Origin version 8.5 (Origin Lab Corp., USA). The significant differences in parameters were evaluated by Duncan's multiple range tests. Table 1, Table 2 and Table 3 were subjected to one-way analysis of variance (ANOVA) using SPSS version 22.0 (IBM Corp., Armonk, NY, USA).

\section{Results}

\subsection{Fermentation treatment}

The effect of fermentation on protein breakdown of zein was analyzed by SDS-PAGE (Figure 1). It can be noticed that the protein profile was substantially changed, major components

Table 1. Secondary structure compositions of zein, zein hydrolysate and glycosylated hydrolysate.

\begin{tabular}{|c|c|c|c|c|}
\hline Samples & a-helix(\%) & $\beta$-sheet $(\%)$ & $\beta$-turn $(\%)$ & random coil (\%) \\
\hline Zein & $49.65 \pm 1.78^{c}$ & $12.62 \pm 0.53^{\mathrm{a}}$ & $17.78 \pm 0.91^{c}$ & $20.05 \pm 0.31^{\mathrm{a}}$ \\
\hline Zein hydrolysate & $13.36 \pm 0.84^{\mathrm{b}}$ & $12.35 \pm 0.53^{\mathrm{a}}$ & $11.68 \pm 1.05^{\mathrm{b}}$ & $62.61 \pm 1.62^{\mathrm{b}}$ \\
\hline Glycosylated hydrolysate & $6.25 \pm 0.77^{\mathrm{a}}$ & $16.85 \pm 0.96^{\mathrm{b}}$ & $6.92 \pm 0.79^{\mathrm{a}}$ & $70.38 \pm 0.57^{c}$ \\
\hline
\end{tabular}

Mean \pm SD $(n=3)$ and different letters in one column are significantly different $(p<0.05)$.

Table 2. Amino acid composition of zein, zein hydrolysate and the glycosylated hydrolysate.

\begin{tabular}{|c|c|c|c|c|}
\hline Amino acid & zein & zein hydrolysate & glycosylated hydrolysate & $\mathrm{WHO}^{\mathrm{B}}$ \\
\hline Lys & $0.17 \pm 0.000^{\mathrm{a}}$ & $3.37 \pm 0.001^{\mathrm{b}}$ & $3.92 \pm 0.004^{\mathrm{c}}$ & 4.5 \\
\hline His & $1.02 \pm 0.002^{\mathrm{a}}$ & $1.33 \pm 0.005^{\mathrm{b}}$ & $1.30 \pm 0.005^{\mathrm{b}}$ & 1.5 \\
\hline Ile & $4.83 \pm 0.008^{c}$ & $4.45 \pm 0.009^{\mathrm{b}}$ & $3.48 \pm 0.009^{\mathrm{a}}$ & 3.0 \\
\hline Leu & $17.79 \pm 0.104^{c}$ & $15.68 \pm 0.089^{\mathrm{a}}$ & $16.12 \pm 0.111^{\mathrm{b}}$ & 5.9 \\
\hline Met & $2.06 \pm 0.002^{\mathrm{a}}$ & $1.93 \pm 0.003^{\mathrm{a}}$ & $1.96 \pm 0.006^{\mathrm{a}}$ & 1.6 \\
\hline Phe & $6.38 \pm 0.005^{\mathrm{b}}$ & $4.89 \pm 0.009^{\mathrm{a}}$ & $4.67 \pm 0.017^{\mathrm{a}}$ & \\
\hline Thr & $2.28 \pm 0.001^{\mathrm{a}}$ & $4.00 \pm 0.106^{\mathrm{b}}$ & $5.06 \pm 0.008^{c}$ & 2.3 \\
\hline Val & $3.33 \pm 0.002^{\mathrm{a}}$ & $4.38 \pm 0.006^{\mathrm{b}}$ & $4.75 \pm 0.009^{c}$ & 3.9 \\
\hline Ala & $8.90 \pm 0.007^{\mathrm{a}}$ & $8.89 \pm 0.007^{\mathrm{a}}$ & $8.75 \pm 0.008^{\mathrm{a}}$ & \\
\hline Arg & $2.59 \pm 0.004^{\mathrm{a}}$ & $3.17 \pm 0.006^{\mathrm{b}}$ & $4.62 \pm 0.009^{c}$ & \\
\hline Asx & $3.15 \pm 0.003^{\mathrm{a}}$ & $3.24 \pm 0.006^{\mathrm{a}}$ & $5.22 \pm 0.009^{\mathrm{b}}$ & \\
\hline Pro & $9.14 \pm 0.011^{\mathrm{b}}$ & $9.38 \pm 0.012^{\mathrm{b}}$ & $8.02 \pm 0.009^{a}$ & \\
\hline Glu & $25.31 \pm 0.029^{c}$ & $23.50 \pm 0.016^{\mathrm{b}}$ & $19.49 \pm 0.017^{\mathrm{a}}$ & \\
\hline Cys & $1.10 \pm 0.000^{\mathrm{a}}$ & $1.55 \pm 0.006^{\mathrm{b}}$ & $1.62 \pm 0.005^{\mathrm{b}}$ & 0.6 \\
\hline Met+Cys & $3.16 \pm 0.002^{\mathrm{a}}$ & $3.48 \pm 0.003^{\mathrm{b}}$ & $3.58 \pm 0.006^{\mathrm{b}}$ & 2.2 \\
\hline Gly & $0.78 \pm 0.0^{\mathrm{a}}$ & $1.67 \pm 0.002^{c}$ & $1.40 \pm 0.002^{\mathrm{b}}$ & \\
\hline Ser & $5.58 \pm 0.003^{\mathrm{a}}$ & $6.05 \pm 0.005^{\mathrm{b}}$ & $6.48 \pm 0.011^{c}$ & \\
\hline $\operatorname{Trp}$ & n.d. & n.d. & n.d. & 0.6 \\
\hline Tyr & $5.59 \pm 0.008^{c}$ & $3.09 \pm 0.011^{\mathrm{b}}$ & $2.80 \pm 0.003^{\mathrm{a}}$ & \\
\hline Phe+Tyr & $11.97 \pm 0.012^{c}$ & $7.98 \pm 0.020^{\mathrm{b}}$ & $7.47 \pm 0.020^{\mathrm{a}}$ & 3.0 \\
\hline Essential amino acids & $36.84 \pm 0.124^{\mathrm{a}}$ & $38.7 \pm 0.228^{\mathrm{b}}$ & $39.96 \pm 0.166^{\mathrm{b}}$ & \\
\hline Sulphur containing amino acids & $3.15 \pm 0.002^{\mathrm{a}}$ & $3.48 \pm 0.009^{\mathrm{b}}$ & $3.58 \pm 0.011^{\mathrm{b}}$ & \\
\hline Total HAA ${ }^{\mathrm{A}}$ & $43.53 \pm 0.133^{c}$ & $40.71 \pm 0.138^{\mathrm{b}}$ & $39.01 \pm 0.161^{\mathrm{a}}$ & \\
\hline
\end{tabular}

Note: Mean \pm SD $(n=3)$ and different letters in one row are significantly different ( $<<0.05)$; "n.d." means not detectable. ${ }^{A}$ Total hydrophobic amino acid (HAA): Val, Leu, Pro, Met, Phe and Ile;

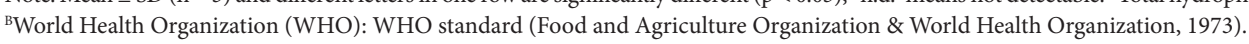


Table 3. In vitro digestibility of zein, zein hydrolysate and the glycosylated hydrolysate.

\begin{tabular}{lccc}
\hline \multicolumn{1}{c}{ Properties } & zein & zein hydrolysate & glycosylated hydrolysate \\
\hline Peptic digestion & $0.111 \pm 0.005^{\mathrm{a}}$ & $0.683 \pm 0.005^{\mathrm{c}}$ & $0.656 \pm 0.007^{\mathrm{b}}$ \\
Peptic-tryptic digestion & $0.193 \pm 0.003^{\mathrm{a}}$ & $0.759 \pm 0.009^{\mathrm{b}}$ & $0.803 \pm 0.004^{\mathrm{c}}$ \\
\hline
\end{tabular}

Note: Mean \pm SD $(n=3)$ and different letters in one row are significantly different $(\mathrm{p}<0.05)$.

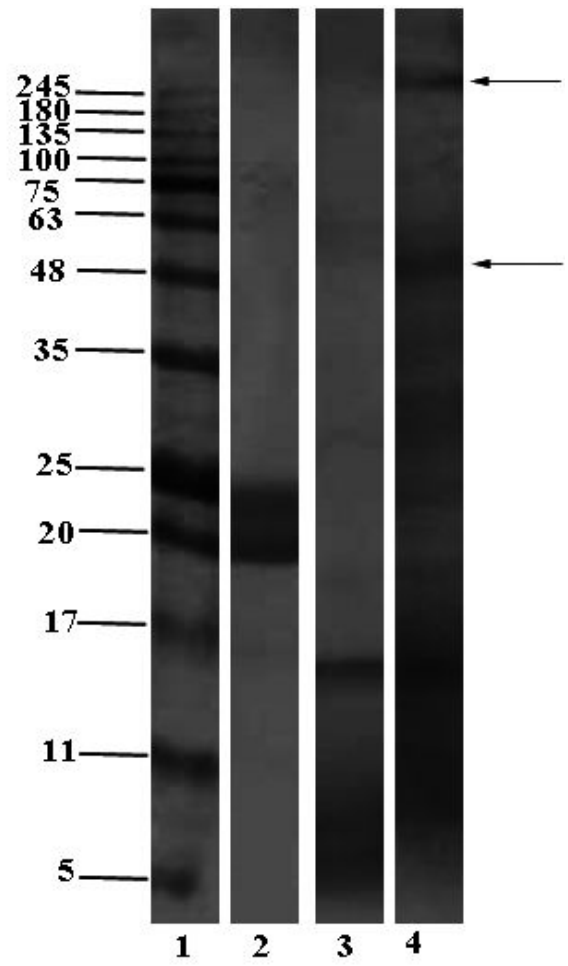

Figure 1. Effect of fermentation on electrophoretic protein profiles. Lanes: Molecular weight standard (1), zein (2), zein hydrolysate (3) and glycosylated hydrolysate (4).

of zein, $25 \mathrm{kDa}$ and $18 \mathrm{kDa}$, disappeared almost totally by fermentation hydrolysis, and the zein hydrolysate was visible in the lower part of gel as a dark area. The indication is zein was hydrolyzed into smaller polypeptides by fermentation (Figure 1). This phenomenon is in agreement with the results of corn glutelin hydrolysate prepared by protamex (Zheng et al., 2015). It is worth to notice that high molecular weight hydrolysate with a dark band above $48 \mathrm{kDa}$ appeared (lane 4 ) at fermentation of $14 \mathrm{~d}$. Fungi can produce microbial TGase during fermentation (Paredes-López et al., 1988). Amino sugars have been found in the cell wall of fungi (Dereggi \& Bauer, 2013). Therefore, we speculated that hydrolysate with high-molecular-weight might be due to glycosylation taking place during liquid fermentation.

\subsection{Characteristics of the glycosylated hydrolysate}

FTIR has been widely used to study molecular structure of glycosylated protein in food science. The observed changes in the FTIR of zein, zein hydrolysate and the glycosylated hydrolysate are shown in Figure 2A. The band around 1400 $\mathrm{cm}^{-1}$ is assigned as the symmetric stretch in $\mathrm{COO}^{-}$functional
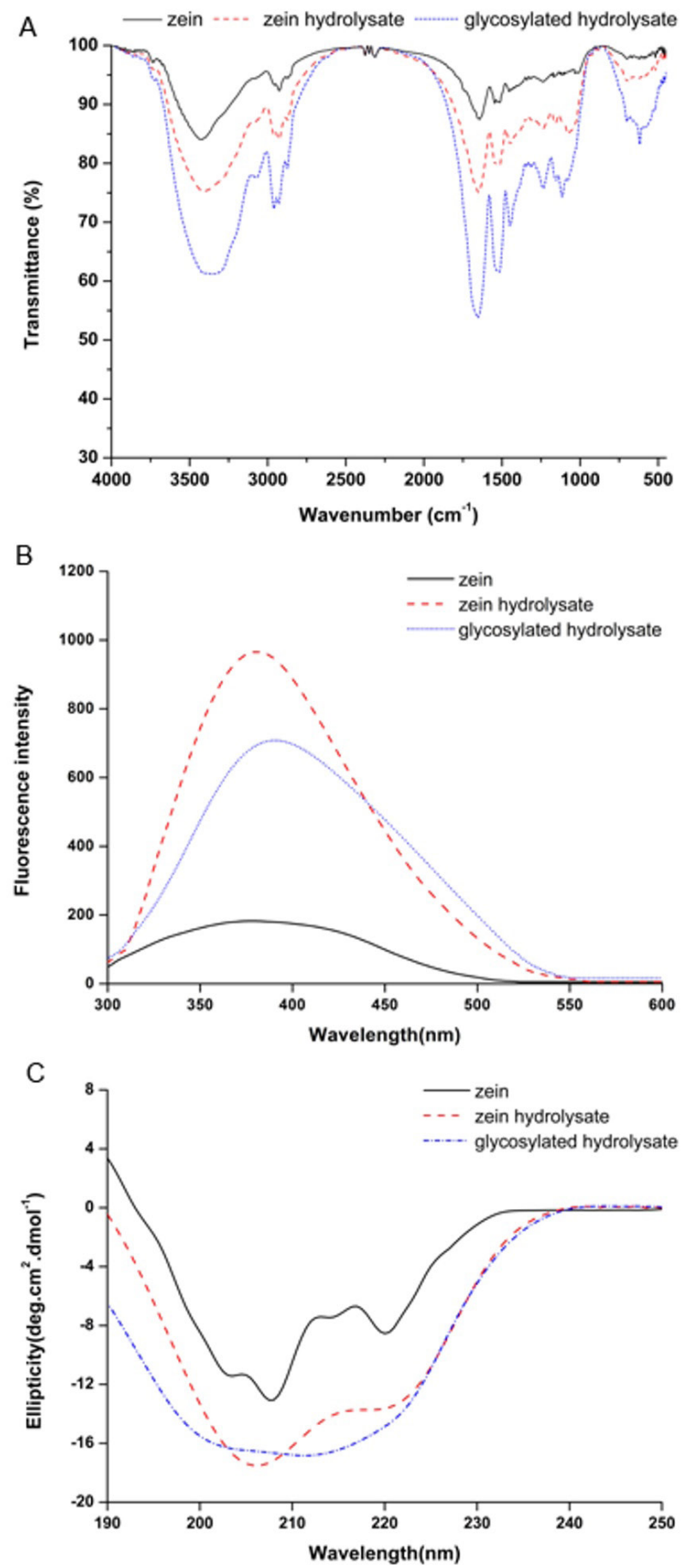

Figure 2. Fourier transform infrared spectra of zein, zein hydrolysate and the glycosylated hydrolysate (A), Intrinsic fluorescence emission spectra of zein, zein hydrolysate and the glycosylated hydrolysate (B) and Circular dichroism spectra of zein, zein hydrolysate and the glycosylated hydrolysate (C). 
groups (Poulsen et al., 2016), while the band at $1516 \mathrm{~cm}^{-1}$ is attributed to the $-\mathrm{NH}^{3+}$ scissoring vibrational mode (Perros et al., 2013). The intensity of bands at $1400 \mathrm{~cm}^{-1}$ and $1516 \mathrm{~cm}^{-1}$ of zein hydrolysate was higher than that of zein, indicating the breakdown of amide backbone and formation of amino and carboxylate terminals. The enhanced absorbance at $1075.74 \mathrm{~cm}^{-1}$ demonstrated the glycosylated hydrolysate contained more $\mathrm{C}-\mathrm{OH}$ than zein hydrolysate. This result proved that some saccharides conjugated to zein hydrolysate during the liquid fermentation.

The emission fluorescence spectroscopic analysis was applied to characterize the conformational changes of zein, zein hydrolysate and the glycosylated hydrolysate. The results are shown in Figure 2B. It can be observed that zein exhibited a strong fluorescence emission peak at $374 \mathrm{~nm}$ after being excited at $280 \mathrm{~nm}$, which was greatly affected by fermentation. The relative fluorescence intensity of zein hydrolysate and the glycosylated hydrolysate showed significant increase. The similar result was also reported by Polanco-Lugo et al. (2014), who thought that hydrolysis induced exposure of the amino acid residues buried within the native structure of Phaseolus lunatus protein, which leaded to an increase in fluorescence intensity. In Figure 2B, the maximum emission fluorescence intensity of zein was found at $374 \mathrm{~nm}$. The zein hydrolysate and glycosylated hydrolysate shifted the maximum wavelength of the emission fluorescence of the control to higher values. This red shift indicated an increase in the polarity of Trp due to molecular unfolding by hydrolyzing. However, the fluorescence intensity of glycosylated hydrolysate showed a decreased tendency in comparison to zein hydrolysate, which could be ascribed to the glycosylation. Glycosylated sugar molecules have steric effect, shielding signals of tryptophan and phenylalanine, which can cause decrease in fluorescence intensity. This phenomenon is consistent with the report of Pedrosa et al. (Pedrosa et al., 1997) who studied the glycosylation reaction of $\beta$-lactoglobulin and cyclodextrin and also found decrease in protein fluorescence intensity.

CD spectroscopy was used to evaluate the secondary structure of zein, zein hydrolysate and the glycosylated hydrolysate. The CD spectra of original zein has two characteristic broad negative bands in the range of 200-230 nm, analogous to the finding by Cuixia Sun et al. (2016). The secondary structure compositions of zein, zein hydrolysate and the glycosylated hydrolysate were shown in Table 1 . The native zein secondary structure composition was $49.65 \%$ a-helix, $12.62 \% \beta$-sheet, $17.78 \% \beta$-turn, and $20.05 \%$ random coil. Occurrence of secondary structures changes has been found after glycosylation and $\alpha$-helix structure was strikingly decreased corresponding to the increase of unordered structure, consistent with the observation for $\beta$-Lactoglobulin-chlorogenic acid conjugates (Fan et al., 2017). $\alpha$-helix is usually buried in the interior site of polypeptide chains (Xue et al., 2013). These results confirmed that saccharides conjugated to zein hydrolysate and zein hydrolysate were partly unfolded by glycosylation which might lead to the exposure of interior amino acids, which was consistent with the results of florescence spectra (Figure 2B). Additionally, Glycosylation induced an obvious increase in $\beta$-sheet, changed from $11.84 \%$ to $16.89 \%$. Xiaopeng Geng et al. (2014) prepared and characterized of ovalbumin and carboxymethyl cellulose conjugates via glycosylation, and also found that $\beta$-sheet and random coil increased while $\alpha$-helix decreased in the ovalbumin structure.

The amino acid compositions of zein, zein hydrolysate and the glycosylated hydrolysate were shown in Table 2. Zein is insolubility in water, which is due to its amino acid composition (Table 2). Zein is particularly rich in glutamic acid (25.31\%), leucine (17.79\%), proline (9.14\%) and alanine (8.9\%), but deficient in lysine $(0.17 \%)$. In addition, the total hydrophobic amino acid of zein was as high as $43.53 \mathrm{~g} / 100 \mathrm{~g}$ protein. The content of total hydrophobic amino acid in the glycosylated hydrolysate decreased to $39.01 \mathrm{~g} / 100 \mathrm{~g}$ protein. Glycosylated hydrolysate had ratio of Lys, His and Ile close to that recommended by the World Health Organization (Food and Agriculture Organization \& World Health Organization (1973), Table 2). The notable absence of lysine in zein accounts for its negative dietary nitrogen balance. The content of lysine in the glycosylated hydrolysate significantly increased compared with zein $(\mathrm{p}<0.05)$, which is higher than zein hydrolysate by the study of Youling L. Xiong (Kong \& Xiong, 2006) (from 0.12 to $0.17 \mathrm{~g} / 100 \mathrm{~g}$ ). Paredes-López et al. (1988) reported that Lys was released in higher amounts during fermentation. They stated that the conversion of amino acids by the action of TGase produced by the fungus could account for this change. Glu content in the glycosylated hydrolysate showed significant decrease compared with zein hydrolysate $(\mathrm{p}<0.05)$, which also implied the occurrence of glycosylation reaction. Since zein hydrolysate contains high proportion of glutamine (23.5\%), the glycosylation reaction can occur mainly between zein hydrolysate and saccharides during liquid fermentation.

\subsection{The impacts of glycosylation on its partial physicochemical properties}

Undesirable solubility of zein restricts its application in food industry. Therefore, the improvement of solubility of zein is a prerequisite for the performance of its other functional properties. Solubility of zein, zein hydrolysate, and the glycosylated hydrolysate in $\mathrm{pH}$ range of $2-14$ is shown in Figure $3 \mathrm{~A}$. The zein showed poor solubility at $\mathrm{pH}<12.0$, and the solubility was under $3 \%$. The poor solubility was due to the rigid structure of zein which contained higher intermolecular, intramolecular disulphide bonds and hydrophobic interactions. The food industry demands high solubility across a wide range of $\mathrm{pH}$. The glycosylated hydrolysate showed higher solubility than that of zein hydrolysate ( $\mathrm{p}<0.05)$, especially for that at $\mathrm{pH}$ of 2-6.

Surface hydrophobicity has important influences on macromolecule structural stability, surface property and fat-binding ability of protein. Figure 3B shows the results of surface hydrophobicity of three samples. The surface hydrophobicity of zein hydrolysate increased by 462.05 compared with zein. It is well known that controlled enzymatic hydrolysis can expose hydrophobic groups hitherto concealed in globular proteins (Wu et al., 1998). This resulted could be ascribed to exposure of hydrophobic amino acid residues buried within the tertiary structure of original zein molecules. However, the surface hydrophobicity of the glycosylated hydrolysate decreased by 604.11 compared with zein hydrolysate. 



Figure 3. Solubility profile of zein, zein hydrolysate and the glycosylated hydrolysate in $\mathrm{pH}$ range of 2-14 (A); Surface hydrophobicity of zein, zein hydrolysate and the glycosylated hydrolysate (B).

Referring to these measured values of digestibility, zein showed greater resistance to both peptic and peptic-tryptic digestion than that of zein hydrolysate and glycosylated hydrolysate $(\mathrm{P}<0.05)$ (Table 3). The detected TCA-soluble nitrogen released from zein hydrolysate and glycosylated hydrolysate are 0.683 and 0.759 (peptic digestion) or 0.656 and 0.803 (peptic-tryptic digestion), respectively, while that from zein is 0.111 and 0.193 . Higher TCA soluble nitrogen is released from zein hydrolysate and glycosylated hydrolysate; that is, both zein hydrolysate and glycosylated hydrolysate have higher digestibility than original zein. Additionally, glycosylated hydrolysate presented lower digestion than zein hydrolysate during peptic digestion. Roos et al. (2003) stated that protein crosslinking would sterically shield the peptide bonds against proteolysis, and resulted in decreased in vitro digestibility.

\subsection{Antioxidant activity of the glycosylated hydrolysate}

Antioxidants are important in health as well as food preservation. Food and pharmaceutical industries often use synthetic antioxidants in their products, however; there is an interest for finding safe and potent natural antioxidants. In this study, we evaluated the antioxidant activities of the glycosylated hydrolysate using four different assays: DPPH/ABTS/superoxide/radical scavenging capacities and $\mathrm{Cu}^{2+}$ chelating capacity. Zein, zein hydrolysate and $\mathrm{Vc}$ were used as controls.

As shown in Figure 4, the original zein did not exhibit DPPH, ABTS and superoxide radicals scavenging activities, however, it possessed weak $\mathrm{Cu}^{2+}$ chelating capacity. Wang et al. (2017) also found original zein showed weak metal ion-chelating activity. The antioxidant values of zein hydrolysate showed significant increase compared with that of zein $(\mathrm{p}<0.05)$. The antioxidant values of glycosylated hydrolysate displayed significant differences compared with that of the zein hydrolysate. The glycosylation reaction significantly improved all the antioxidant values of zein hydrolysate except DPPH radical scavenging activity, and the antioxidant efficiency of the glycosylated hydrolysate was concentration dependent. No significant increase was observed in the concentration within $0.25-1 \mathrm{mg} / \mathrm{mL}$. The ABTS radical scavenging capacity of glycosylated hydrolysate was greater than that of $2-4 \mathrm{mg} / \mathrm{mL}$ of zein hydrolysate $(\mathrm{p}<0.05)$. The glycosylated hydrolysate showed significant increase in $\mathrm{Cu}^{2+}$ chelating capacities than that of $2-4 \mathrm{mg} / \mathrm{mL}$ of zein hydrolysate $(\mathrm{p}<0.05)$. The superoxide radical scavenging capacity of zein hydrolysate increased slightly after glycosylation. The results established glycosylated hydrolysate, at the concentration tested $(2-4 \mathrm{mg} / \mathrm{mL})$, to be effective hydrogen or electron donors.

\section{Discussion}

The physicochemical and functional properties of hydrolyzed proteins and peptides have been well-documented in the literature, but no study has been conducted to evaluate the properties of glycosylated hydrolysate prepared by fermentation. Therefore, partial properties of glycosylated hydrolysate were evaluated.

Glycosylated hydrolysate exhibited better solubility in $\mathrm{pH}$ 2-14. Compared with the zein hydrolysate, the improved solubility of the glycosylated hydrolysate might be attributed to the increase in hydrophilic groups (i.e. hydroxyl groups in the attached saccharides) by glycosylation. Jiang \& Zhao (2010) reported that cross-linking and glucosamine conjugation improved caseinate solubility. A similar solubility improvement was also observed for soybean protein-galactomannan conjugates (Babiker et al., 1998). The two reported results provided support to the present result. In addition, the changes in conformation of structure also can explain the reason for increasing in solubility. Solubility of proteins is influenced by $\mathrm{pH}$, ionic strength, type of salts, and protein conformation (Sirison et al., 2017). According to the results of conformation analysis (Figure 2B) the unfolding of the glycosylated hydrolysate chains and loosening tertiary conformation might promote intramolecular hydration of proteins. These structural changes resulted in an improvement of glycosylated hydrolysate-water interaction, thus increasing the solubility. Thus, the glycosylation derived from fermentation can be used as an effective technique to further improve the solubility of zein. Crosslinking of protein by TGase might cause an impaired digestibility in vitro (Jiang \& Zhao, 2010). Glycosylated hydrolysate presented lower digestion than zein hydrolysate during peptic digestion. However, glycosylated hydrolysate showed higher digestion $(\mathrm{P}<0.05)$ than zein hydrolysate during peptic-tryptic digestion. Binding of saccharides into protein molecules would result in partial unfolding structures (Figure 2), 

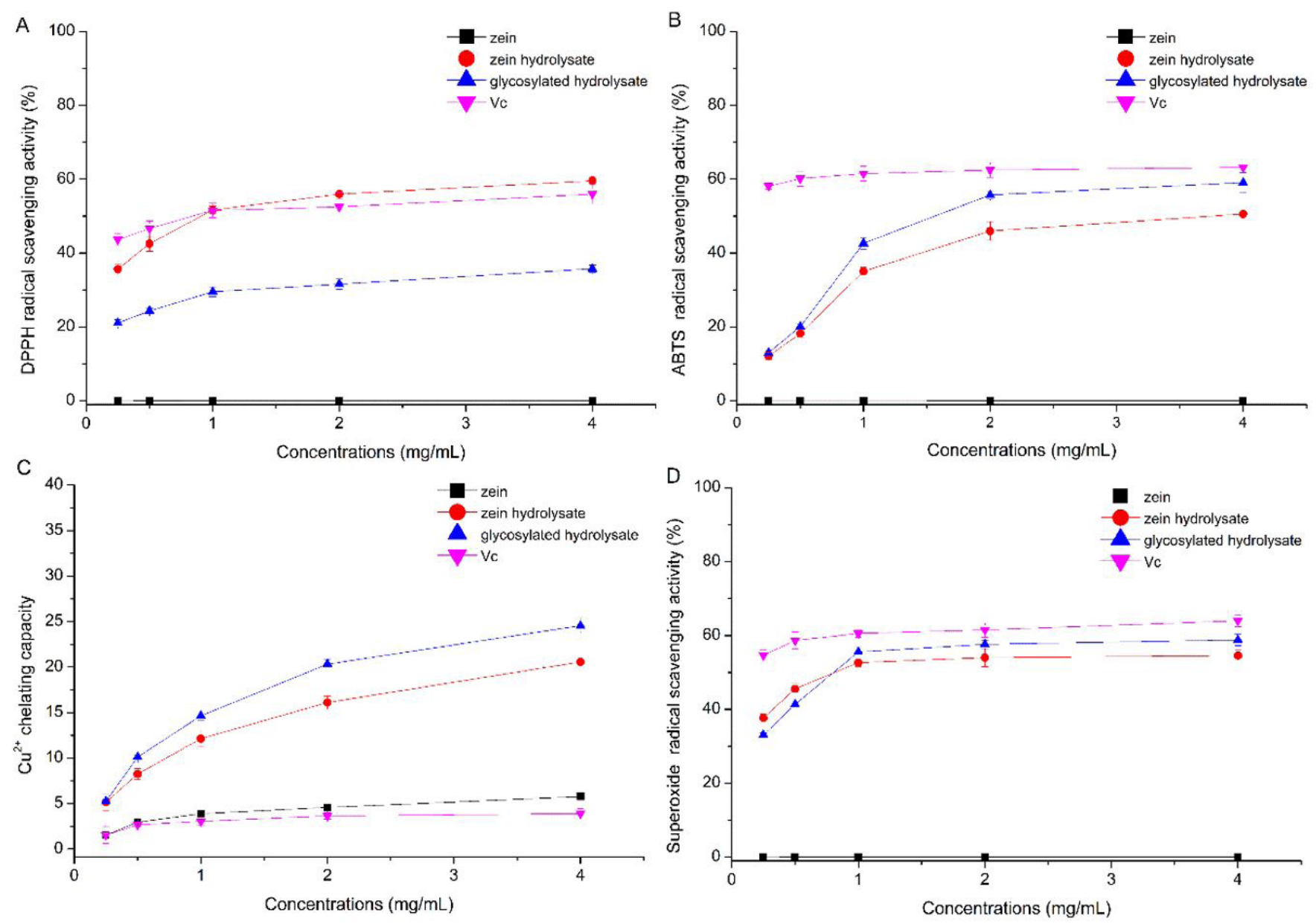

Figure 4. Effects of zein, zein hydrolysate, glycosylated hydrolysate and Vc on DPPH radical scavenging activity (A), ABTS radical scavenging activity (B), Cu2+ chelating capacity (C) and superoxide radical scavenging activity (D), respectively.

which was beneficial to the proteolysis of protein-saccharide conjugates. Wang et al. (2007) reported that dextran conjugation unfolded $\beta$-lactoglobulin molecules and consequentially elevated their enzymatic susceptibility. At the same time, glycosylated hydrolysate had lower surface hydrophobicity (about 2914.11) than zein hydrolysate (about 3518.05) or zein (about 3056.14) (Figure 3B). It could be speculated that the decreased surface hydrophobicity of the glycosylated hydrolysate was a result of an increased number of hydrophilic groups in the side chains of the zein hydrolysate by saccharide conjugation. Wang et al. (2017) studied glycosylation between zein and chitosan catalyzed by TGase and found that the modified product exhibited lower surface hydrophobicity. These results indicated that glycosylation conferred glycosylated hydrolysate better solubility and higher enzymatic digestion.

The glycosylation reaction significantly improved all the antioxidant values of zein hydrolysate except DPPH radical scavenging activity. Different mechanisms of oxidation occur in the different assays, as outlined elsewhere (Thiansilakul et al., 2007). Therefore, it is understandable that antioxidant ability varied in the glycosylated hydrolysate between assays. The scavenging patterns for DPPH radical were likely related to the structure of peptides produced at different stages. DPPH radical is an oil-soluble free radical that becomes a stable product after accepting an electron or a hydrogen from an antioxidant (Zhu et al., 2008). After the glycosylation reaction, more hydrophobic amino residue side chain groups might be hid; therefore, glycosylated hydrolysate became less accessible by DPPH radical. This would impair electron transfer from glycosylated hydrolysate, thereby decreasing DPPH radical scavenging activity. Taking the three assays together, however, glycosylated hydrolysate appeared to have the greatest overall antioxidant ability. These activities might depend mainly on the saccharides moiety of the glycosylated hydrolysate, which could discontinue the free radical chain reaction by donating more protons to react with free radicals and/or limit the production of radicals by binding copper as metal chelator to stabilize them in an inactive form. In the literature available, antioxidant activity of the glycosylated hydrolysate prepared by fermentation has not been reported so far. Some results of researchers clearly showed that fungal saccharides displayed antioxidant activity (Paterson, 2008). The glycosylated hydrolysate of $1 \mathrm{mg}$ contained about saccharides of $0.065 \mathrm{mg}$. The antioxidant efficiency of the glycosylated hydrolysate of $1 \mathrm{mg}$ was significantly higher than that of the zein hydrolysate of $1 \mathrm{mg}$. These results suggest that the glycosylated hydrolysate possesses fine antioxidant activity, which could be due to the some saccharides conjugated to the zein hydrolysate. 


\section{Conclusion}

In this study, the results of SDS-PAGE and FTIR demonstrated the occurrence of glycosylation reaction. Intrinsic fluorescence emission spectra and Circular dichroism analyses demonstrated that the glycosylated hydrolysate contained more-OH groups, and had a more open secondary structure. Glycosylated hydrolysate exhibited an enhanced solubility, in vitro digestibility, and antioxidant activities, but decrease in surface hydrophobicity, compared with that of zein and zein hydrolysate. These results demonstrated that glycosylation derived from liquid fermentation might be a new approach to modify partial functional properties of zein, and the glycosylated hydrolysate could be used as natural antioxidant.

\section{Acknowledgements}

This work was supported by the National Key R\&D Program of China (Grant Number: 2016YFD0400702).

\section{References}

Babiker, E. E., Hiroyuki, A., Matsudomi, N., Iwata, H., Ogawa, T., Bando, N., \& Kato, A. (1998). Effect of polysaccharide conjugation or transglutaminase treatment on the allergenicity and functional properties of soy protein. Journal of Agricultural and Food Chemistry, 46(3), 866-871. http://dx.doi.org/10.1021/jf9705072.

Chuacharoen, T., \& Sabliov, C. M. (2016). The potential of zein nanoparticles to protect entrapped $\beta$-carotene in the presence of milk under simulated gastrointestinal (GI) conditions. LebensmittelWissenschaft + Technologie, 72, 302-309. http://dx.doi.org/10.1016/j. lwt.2016.05.006.

Dereggi, A. S., \& Bauer, S. (2013). Development of a compound specific stable isotope method for amino sugars as tracers of microbial dynamics in terrestrial ecosystems (Doctoral thesis). Ghent University, Belgium.

Du, Y. L., Huang, G. Q., Wang, H. O., \& Xiao, J.-X. (2018). Effect of high coacervation temperature on the physicochemical properties of resultant microcapsules through induction of Maillard reaction between soybean protein and chitosan. Journal of Food Engineering, 234, 91-97. http://dx.doi.org/10.1016/j.jfoodeng.2018.04.020.

Fan, Y., Zhang, Y., Yokoyama, W., \& Yi, J. (2017). $\beta$-Lactoglobulinchlorogenic acid conjugate-based nanoparticles for delivery of (-)-epigallocatechin-3-gallate. RSC Advances, 7(35), 21366-21374. http://dx.doi.org/10.1039/C6RA28462K.

Food and Agriculture Organization - FAO, \& World Health Organization - WHO. (1973). Energy and protein requirements [R] (Report of a Joint FAO/WHO Ad Hoc Expert Committee). Geneva: WHO.

Geng, X., Cui, B., Li, Y., Jin, W., An, Y., Zhou, B., Ye, T., He, L., Liang, H., Wang, L., Chen, Y., \& Li, B. (2014). Preparation and characterization of ovalbumin and carboxymethyl cellulose conjugates via glycosylation. Food Hydrocolloids, 37(37), 86-92. http://dx.doi.org/10.1016/j. foodhyd.2013.10.027.

Hrynets, Y., Ndagijimana, M., \& Betti, M. (2013). Non-enzymatic glycation of natural actomyosin (NAM) with glucosamine in a liquid system at moderate temperatures. Food Chemistry, 139(14), 1062-1072. http://dx.doi.org/10.1016/j.foodchem.2013.02.026. PMid:23561210.

Jiang, J., Zhang, Z., Zhao, J., \& Liu, Y. (2018). The effect of non-covalent interaction of chlorogenic acid with whey protein and casein on physicochemical and radical-scavenging activity of, in vitro, protein digests. Food Chemistry, 268, 334-341. http://dx.doi.org/10.1016/j. foodchem.2018.06.015. PMid:30064766.

Jiang, S., \& Zhao, X. (2010). Transglutaminase-induced cross-linking and glucosamine conjugation in soybean protein isolates and its impacts on some functional properties of the products. European Food Research and Technology, 231(5), 679-689. http://dx.doi. org/10.1007/s00217-010-1319-2.

Kim, J. (2013). Antioxidant activity of Maillard reaction products derived from aqueous and ethanolic glucose-glycine and its oligomer solutions. Food Science and Biotechnology, 22(1), 39-46. http://dx.doi. org/10.1007/s10068-013-0006-Z.

Kong, B., \& Xiong, Y. L. (2006). Antioxidant activity of zein hydrolysates in a liposome system and the possible mode of action. Journal of Agricultural and Food Chemistry, 54(16), 6059-6068. http://dx.doi. org/10.1021/jf060632q. PMid:16881717.

Kraehenbuehl, K., Davidek, T., Devaud, S., \& Mauroux, O. (2010). Basic and acidic sugars as flavour precursors in the maillard reaction. Retrieved from https://www.researchgate.net/publication/236846371

Matemu, A. O., Kayahara, H., Murasawa, H., \& Nakamura, S. (2009). Importance of size and charge of carbohydrate chains in the preparation of functional glycoproteins with excellent emulsifying properties from tofu whey. Food Chemistry, 114(4), 1328-1334. http://dx.doi. org/10.1016/j.foodchem.2008.11.011.

Maux, S. L., Nongonierma, A. B., Lardeux, C., \& FitzGerald, R. J. (2018). Impact of enzyme inactivation conditions during the generation of whey protein hydrolysates on their physicochemical and bioactive properties. International Journal of Food Science \& Technology, 53(1) https://doi.org/10.1111/ijfs.13576.

Ozturk, O. K., \& Mert, B. (2018). The use of microfluidization for the production of xanthan and citrus fiber-based gluten-free corn breads. Lebensmittel-Wissenschaft + Technologie, 96, 34-41. http:// dx.doi.org/10.1016/j.lwt.2018.05.025.

Paredes-López, O., Harry, G. I., \& Murray, E. D. (1988). Food biotechnology review: Traditional solid-state fermentations of plant raw materials - application, nutritional significance, and future prospects. Critical Reviews in Food Science and Nutrition, 27(3), 159-187. http://dx.doi. org/10.1080/10408398809527483. PMid:3067978.

Paterson, R. R. M. (2008). Cordyceps - a traditional Chinese medicine and another fungal therapeutic biofactory? Phytochemistry, 69(7), 1469-1495. http://dx.doi.org/10.1016/j.phytochem.2008.01.027. PMid:18343466.

Pedrosa, C., Trisciuzzi, C., \& Ferreira, S. T. (1997). Effects of Glycosylation on Functional Properties of Vicilin, the 7S Storage Globulin from Pea (Pisum sativum). Journal of Agricultural and Food Chemistry, 45(45), 2025-2030. http://dx.doi.org/10.1021/jf960815k.

Perros, A. P., Hakola, H., Sajavaara, T., Huhtio, T., \& Lipsanen, H. (2013). Influence of plasma chemistry on impurity incorporation in AlN prepared by plasma enhanced atomic layer deposition. Journal of Physics. D, Applied Physics, 46(50), 502-505. http://dx.doi. org/10.1088/0022-3727/46/50/505502.

Polanco-Lugo, E., Dávila-Ortiz, G., Betancur-Ancona, D. A., \& ChelGuerrero, L. A. (2014). Effects of sequential enzymatic hydrolysis on structural, bioactive and functional properties of Phaseolus lunatus protein isolate. Food Science and Technology (Campinas), 34(3), 441-448. http://dx.doi.org/10.1590/1678-457x.6349.

Poulsen, N. A., Eskildsen, C. E., Akkerman, M., Johansen, L. B., Hansen, M. S., Hansen, P. W., Skov, T., \& Larsen, L. B. (2016). Predicting hydrolysis of whey protein by mid-infrared spectroscopy. International Dairy Journal, 61, 44-50. http://dx.doi.org/10.1016/j. idairyj.2016.04.002. 
Ranamukhaarachchi, S. A., Peiris, R. H., \& Moresoli, C. (2017). Fluorescence spectroscopy and principal component analysis of soy protein hydrolysate fractions and the potential to assess their antioxidant capacity characteristics. Food Chemistry, 217, 469-475. http://dx.doi.org/10.1016/j.foodchem.2016.08.029. PMid:27664660.

Re, R., Pellegrini, N., Proteggente, A., Pannala, A., Yang, M., \& RiceEvans, C. (1999). Antioxidant activity applying an improved ABTS radical cation decolorization assay. Free Radical Biology \& Medicine, 26(9-10), 1231-1237. http://dx.doi.org/10.1016/S0891-5849(98)003153. PMid:10381194.

Roos, N., Lorenzen, P. C., Sick, H., Schrezenmeir, J., \& Schlimme, E. (2003). Cross-linking by transglutaminase changes neither the in vitro proteolysis nor the in vivo digestibility of caseinate. Kieler Milchwirtschaftliche Forschungsberichte, 55(4), 261-276.

Sirison, J., Matsumiya, K., Samoto, M., Hidaka, H., Kouno, M., \& Matsumura, Y. (2017). Solubility of soy lipophilic proteins: comparison with other soy protein fractions. Bioscience, Biotechnology, and Biochemistry, 81(4), 790-802. http://dx.doi.org/10.1080/09168451. 2017.1282808. PMid:28300503.

Sun, C., Dai, L., He, X., Liu, F., Yuan, F., \& Gao, Y. (2016). Effect of heat treatment on physical, structural, thermal and morphological characteristics of zein in ethanol-water solution. Food Hydrocolloids, 58, 11-19. http://dx.doi.org/10.1016/j.foodhyd.2016.02.014.

Thiansilakul, Y., Benjakul, S., \& Shahidi, F. (2007). Compositions, functional properties and antioxidative activity of protein hydrolysates prepared from round scad (Decapterus maruadsi). Food Chemistry, 103(4), 1385-1394. http://dx.doi.org/10.1016/j.foodchem.2006.10.055.

Wang, J.-S., Zhao, M.-M., Yang, X.-Q., Jiang, Y.-M., \& Chun, C. (2007). Gelation behavior of wheat gluten by heat treatment followed by transglutaminase cross-linking reaction. Food Hydrocolloids, 21(2), 174-179. http://dx.doi.org/10.1016/j.foodhyd.2006.03.006.

Wang, X. J., Zheng, X. Q., Liu, X. L., Kopparapu, N. K., Cong, W. S., \& Deng, Y. P. (2017). Preparation of glycosylated zein and retarding effect on lipid oxidation of ground pork. Food Chemistry, 227, 335-341. http://dx.doi.org/10.1016/j.foodchem.2017.01.069. PMid:28274441.

Wang, X., Zheng, X., Kopparapu, N., Cong, W., Deng, Y., Sun, X., \& Liu, X. (2014). Purification and evaluation of a novel antioxidant peptide from corn protein hydrolysate. Process Biochemistry, 49(9), 1562-1569. http://dx.doi.org/10.1016/j.procbio.2014.05.014.

Wu, W. U., Hettiarachchy, N. S., \& Qi, M. (1998). Hydrophobicity, solubility, and emulsifying properties of soy protein peptides prepared by papain modification and ultrafiltration. Journal of the American Oil Chemists' Society, 75(7), 845-850. http://dx.doi.org/10.1007/ s11746-998-0235-0.

Xia, Y., Bamdad, F., Gänzle, M., \& Chen, L. (2012). Fractionation and characterization of antioxidant peptides derived from barley glutelin by enzymatic hydrolysis. Food Chemistry, 134(3), 1509-1518. http://dx.doi.org/10.1016/j.foodchem.2012.03.063. PMid:25005974.

Xue, F., Li, C., Zhu, X., Wang, L., \& Pan, S. (2013). Comparative studies on the physicochemical properties of soy protein isolate-maltodextrin and soy protein isolate-gum acacia conjugate prepared through Maillard reaction. Food Research International, 51(2), 490-495. http://dx.doi.org/10.1016/j.foodres.2013.01.012.

Yang, S., Zheng, M., Cao, Y., Dong, Y., Yaqoob, S., \& Liu, J. (2018). Optimization of liquid fermentation conditions for biotransformation zein by Cordyceps militaris 202 and characterization of physicochemical and functional properties of fermentative hydrolysates. Brazilian Journal of Microbiology, 49(3), 621-631. http://dx.doi.org/10.1016/j. bjm.2017.12.005. PMid:29452848.

Zhao, G., Liu, Y., Zhao, M., Ren, J., \& Yang, B. (2011). Enzymatic hydrolysis and their effects on conformational and functional properties of peanut protein isolate. Food Chemistry, 127(4), 1438-1443. http:// dx.doi.org/10.1016/j.foodchem.2011.01.046.

Zheng, X. Q., Wang, J. T., Liu, X. L., Sun, Y., Zheng, Y. J., Wang, X. J., \& Liu, Y. (2015). Effect of hydrolysis time on the physicochemical and functional properties of corn glutelin by Protamex hydrolysis. Food Chemistry, 172, 407-415. http://dx.doi.org/10.1016/j. foodchem.2014.09.080. PMid:25442571.

Zhu, L., Chen, J., Tang, X., \& Xiong, Y. L. (2008). Reducing, radical scavenging, and chelation properties of in vitro digests of alcalase-treated zein hydrolysate. Journal of Agricultural and Food Chemistry, 56(8), 2714-2721. http://dx.doi.org/10.1021/jf703697e. PMid:18376842. 